\title{
DESAFIOS E PROTAGONISMO: FISIOTERAPIA INSPIRANDO NOVOS FUTUROS
}

\author{
CHALLENGES AND PROTAGONISM: PHYSIOTHERAPY INSPIRING NEW FUTURES
}

DOI: $10.16891 / 2317-434$ X.v.10.e1.a2022.pp1158-1159

Francisca Alana de Lima Santos

Centro Universitário Doutor Leão Sampaio

A fisioterapia, ciência que estuda, previne e trata alterações cinético-funcionais já atingiu seu jubileu. Contudo, suas origens assomam aos meados do século XX, quando em meio a $2^{\mathrm{a}}$ guerra mundial, houve a necessidade de reintegrar à sociedade funcional, aqueles que outrora foram mutilados no combate (CREFITO 3, 2011). Se regressarmos no tempo podemos notar a presença desse saber em momentos importantes de necessidade mundial, como após a revolução industrial, principalmente na Inglaterra, ainda identificados como massagistas, com atuação nas famosas Casas de Massagem (NICHOLLS; CHEEK, 2006), ou até em eventos mais locais, como no surto de Poliomielite no Brasil (REIS; TEIXEIRA, 2016).

Em 2020 o mundo passa por mais uma intempérie: a COVID-19. Surgida em Wuhan, uma série de pneumonias que posteriormente seriam identificadas como COVID-19, a patologia causada pelo vírus SARS-CoV-2 trouxe um novo desafio a ser enfrentado: Uma pandemia de escalas nunca antes vista (OMS, 2020). Nesse cenário de caos, diversos profissionais de saúde, dentre eles o fisioterapeuta, são convocados a assumir a linha de frente do cuidado, enfrentando risco de contaminação aumentado, carga de trabalho excessiva, isolamento de familiares e toda uma verdadeira "orquestra" ordenada de Equipamentos de Proteção Individual (EPIs) (OLIVEIRA et al., 2020).

A fisioterapia que antes, a duras penas, conseguiu seu espaço dentro das Unidades de Terapia Intensiva (UTIs), agora, mais do que nunca, era essencial em seus cuidados, atuando desde os processos de ressuscitação cardiopulmonar, mobilização do paciente crítico, monitorização daqueles em ventilação mecânica (VM), ou até mesmo auxiliando a criar recomendações para o manejo desses pacientes (ASSOBRAFIR, 2020). Mas esse protagonismo não estagnou nesse ponto. Vimos o profissional fisioterapeuta se reinventando para dar continuidade aos atendimentos nas diversas áreas de atuação, sejam nas formas presenciais, adotando protocolos sanitários importantes e desafiadores, ou até através do tele monitoramento, fundamental quando a distância e os riscos falavam mais alto.

É fato que a evolução das ciências da saúde acompanha momentos históricos, contudo, quanto a fisioterapia, esse cenário a fez ser vista apenas como reabilitadora por muitos anos (SILVA et al., 2021), perspectiva que aos poucos se modifica. Esse perfil metanoico pela qual passa a fisioterapia, assim como perpassa pelos pensamentos de Oliveira (2015), aponta seu rompimento com o modelo biomédico e sua descoberta como novo profissional, fugindo do perfil apenas curativo e hoje modificando o olhar na construção de um profissional crítico, reflexivo e autônomo, na busca de nova identidade profissional.

A fisioterapia como ciência ganha espaço a cada dia, seja com as contribuições como ciência ou ainda, com a reinserção dos indivíduos à sociedade. E o reconhecimento vem acontecendo. A lei 14.231 prova isso. Oficializada em 28 de outubro de 2021, a lei traz a realidade $\mathrm{o}$ reconhecimento da necessidade, da importância do profissional ao incluir o fisioterapeuta na estratégia de saúde da família (BRASIL, 2021).

Ganha a população, ganha a profissão, ganha a ciência. A fisioterapia vem avançando e crescendo ao quebrar paradigmas e assumindo o protagonismo em tempos de crise. Incorporando ao perfil curativo e reabilitador, a fisioterapia se reinventa e cria novas formas de atuação, inspirando novos futuros na formação de um profissional melhor. A sociedade agradece. 


\section{REFERENCIAS}

ASSOCIAÇÃO BRASILEIRA DE FISIOTERAPIA CARDIORRESPIRATÓRIA E FISIOTERAPIA EM TERAPIA INTENSIVA - ASSOBRAFIR. COVID-19. 2020. Disponível em: <https://assobrafir.com.br/covid19/>. Acesso em: 08 de Outubro de 2021.

BRASIL. Lei $\mathrm{n}^{\circ} 14.231$, de 28 de Outubro de 2021. Inclui os profissionais fisioterapeuta e terapeuta ocupacional na estratégia de saúde da família. Diário Oficial da União: Seção 1, Brasília, DF, p.1, 29 out. 2021.

CONSELHO REGIONAL DE FISIOTERAPIA E DE TERAPIA OCUPACIONAL (CREFITO3). 2011. Disponível em:http://www.crefito3.org.br/dsn/fisioterapia.asp.

Acesso em: 12 de julho de 2021.

NICHOLLS, D. A.; CHEEK, J. Physiotherapy and the shadow of prostitution: The Society of Trained Masseuses and the massage scandals of 1894 . Social Science \& Medicine, n.62, p.2336-48, 2006.

OLIVEIRA, A. L. A Fisioterapia no estado de São Paulo: Um estudo sobre as representações dos profissionais.Tese de Doutorado. Universidade Estadual de Campinas.Faculdade de Ciências Médicas. Campinas, 2015.
OLIVEIRA, E. N.; et al. Com a palavra os profissionais de saúde na linha de frente do combate à COVID19. Research, Society and Development, v. 9, n. 8, p. e30985145-e30985145, 2020.

ORGANIZAÇÃO MUNDIAL DE SAÚDE. Report of the WHO-China Joint Mission on Coronavirus Disease 2019 (COVID-19). 2020. Disponívem em: $<$ https://www.who.int/docs/defaultsource/coronaviruse/who-china-joint-mission-on-covid19-final-report.pdf > . Acesso em: 07 de outubro de 2021.

REIS, V. C.; TEIXEIRA, R. C. A saúde coletiva nas práticas educacionais dos fisioterapeutas docentes do curso de fisioterapia da universidade do estado do Pará. Cadernos de educação, saúde e fisioterapia, v. 3 , n. 5 , p. 671, 2016.

SILVA, R. F.; et al. A origem e evolução da fisioterapia: da antiguidade ao reconhecimento profissional. Revista Ibero-Americana de Humanidades, Ciências e Educação, v. 7, n. 7, p. 782-791, 2021. 